\section{PEER-REVIEWED ARTICLE}

Food Protection Trends, Vol 40, No. 5, p. 296-313 Copyright ${ }^{\oplus} 2020$, International Association for Food Protection 2900 100th Street, Suite 309, Des Moines, IA 50322-3855
Basem Boutros $^{1 *}$ and Kevin Roberts ${ }^{2}$

Dept. of Family and Consumer Sciences College of Health Sciences, Sam Houston State University, 1700 University Ave., Suite 119, Huntsville, TX 77341, USA

${ }^{2}$ Department of Hospitality Management, Kansas State

University, 1324 Lovers Lane, Manhattan, KS 66506, USA

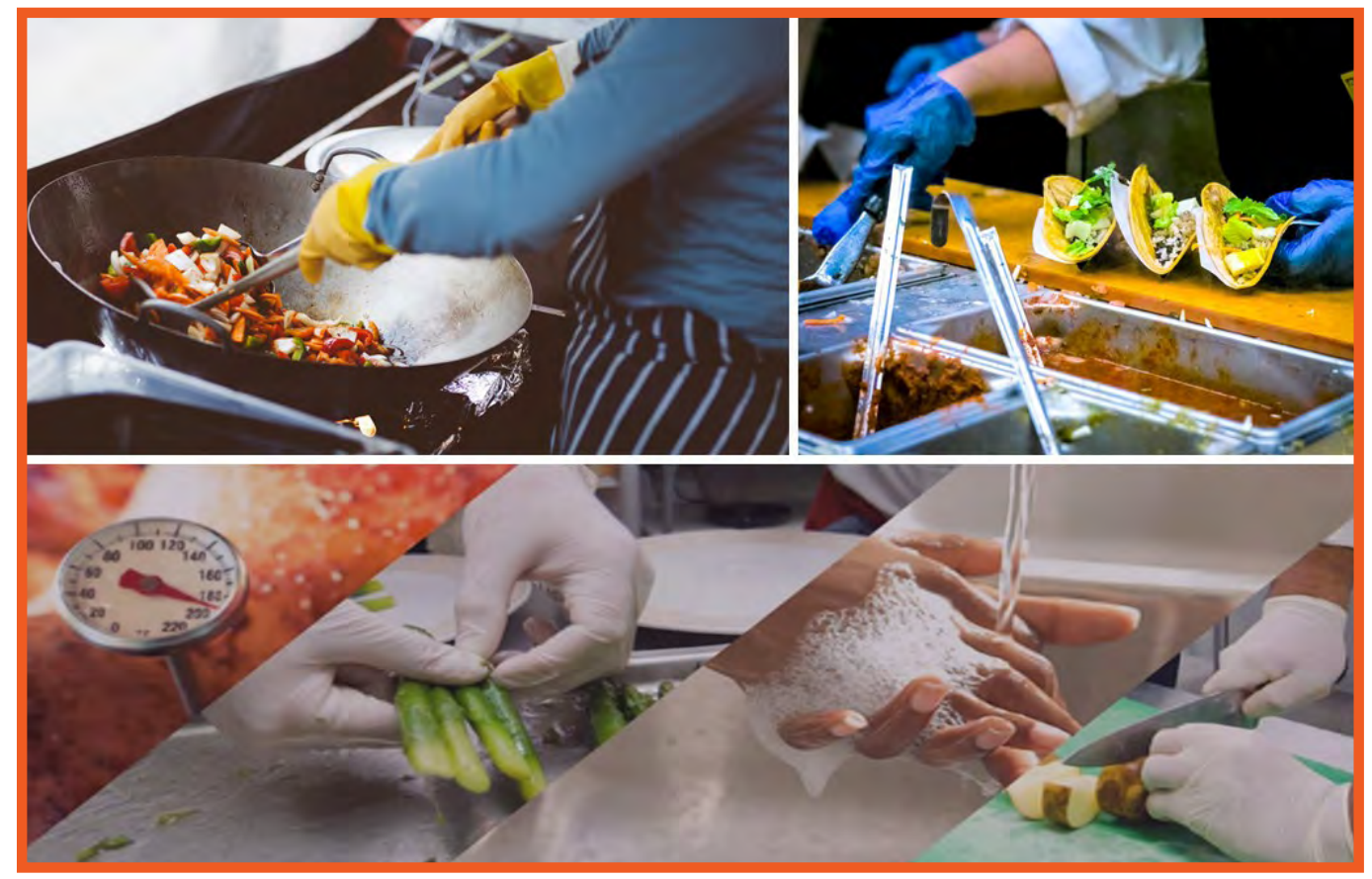

\title{
Self-Reported Food Safety Behaviors in Independent Chinese and Mexican Restaurants in Kansas
}

\section{ABSTRAGT}

Research has shown that food served in ethnic restaurants is frequently associated with foodborne outbreaks. Few studies have used the Social Cognitive Theory to predict food safety behaviors, especially in independent ethnic restaurants. This study aimed to determine whether self-efficacy, self-regulation, outcome expectations, and environmental determinants are predictive of self-reported food safety behaviors through examining the behavioral intentions of food handlers in independent Chinese and Mexican restaurants.

A questionnaire was developed and self-administered. It was translated to Chinese and Spanish and backtranslated to English to ensure accuracy. A multistage random sampling technique was utilized to collect data onsite, targeting a minimum of 250 food handlers from independent Mexican and Chinese restaurants. A total of 204 food handlers responded; 201 responses were usable, for a response rate of $80.4 \%$.

Multiple regression and mediation analyses were used to analyze the data. Only self-regulation, environmental determinants, and outcome expectations were statistically significant predictors of food safety behavioral intentions. Behavioral intentions were a significant mediator of the relationships between all predictors and self-reported food safety behaviors. The findings suggest that self-regulation, outcome expectations, and environmental factors in the form of equipment and supplies can promote positive food safety behaviors through behavioral intentions.

\section{INTRODUCTION}

Ethnic restaurants are defined as those that serve food from countries other than the traditional cuisine of the host country (18). Ethnic restaurants, especially Chinese, Italian, and Mexican have gained popularity and have become mainstream in the diet of most Americans $(3,47,51)$. The ethnic food market continues to grow, with Mexican food having $62 \%$ of the market share (45). The increased interest in ethnic food in the United States has been driven by the diverse population, the growing number of immigrants who seek their traditional food, and young people who like to try new and different foods $(57,64)$. 
Despite the rapid growth in ethnic foods and the popularity of ethnic restaurants, several researchers have noted that ethnic restaurants were associated with foodborne disease outbreaks $(44,45,50)$. Previous research has shown that ethnic restaurants have more violations than non-ethnic restaurants in categories related to time and temperature abuse, cross-contamination, and food that is unadulterated and honestly presented (50). Independent ethnic restaurants were found to have more critical food safety violations than chain ethnic restaurants $(44,56)$. Most independent ethnic restaurants are small-scale businesses that are challenged by their uniqueness as family-owned operations that have few resources for improving food safety (50).

Although food safety knowledge is an essential component of promoting food safety behavior, numerous studies have indicated that increased knowledge is not sufficient for behavior change $(5,59,73)$. Food safety training and regulatory inspections are the two fundamental approaches used to mitigate the risk of foodborne outbreaks in foodservice operations; however, the contributing factors to foodborne diseases, such as improper food handling and inadequate cooking and holding, are behaviors that need to be changed (28). For instance, the most frequently reported food safety violations in independent ethnic restaurants were poor time and temperature control, cross-contamination, poor hand hygiene, and poor physical facility maintenance (43). Therefore, improving food safety requires shifting the focus from the traditional approaches of training and inspection to understanding employees' behavior (62).

The Social Cognitive Theory (SCT) is based on the underlying premise that environmental, personal, and other behavioral factors interact to influence one another in a bidirectional process, termed triadic reciprocal causation (9). The theory proposes that people's behavior is determined by their environment and personal characteristics (24). The researchers further indicated that personal characteristics are formed by behavior that influences a person's environment. The core set of personal and environmental constructs of the SCT includes self-efficacy, which refers to confidence in one's ability to perform a behavior; outcome expectations regarding the expected consequences of a behavior; selfregulation, which refers to the goals individuals set for themselves and the plans and strategies for achieving them; and environmental characteristics in the form of resources, structures, or physical conditions that make behaviors easier to perform (54) and social support as a component of the organizational culture (29). Thus, the SCT posits that individuals perform a behavior if they perceive control over the outcome, perceive few external barriers, and have confidence in their own ability (6). Previous research using a systematic review of 100 behavior theories to identify the theoretical explanations for behavior change maintenance found that the SCT is among the most relevant (41). The importance of the SCT lies in enabling researchers to understand the process by which individuals acquire and perform certain behaviors and in providing the basis for intervention strategies (10).

The SCT has been used to explain and predict a diverse set of health-related behaviors, such as smoking cessation (14), weight reduction and exercise increase (30), and improvement of dietary habits $(4,26)$. However, very little research has been done using the SCT constructs to predict food safety behaviors, especially in independent ethnic restaurants. Factors from social cognition models are important in predicting safe food handling behaviors (63). For instance, self-efficacy alone was the only significant predictor of food safety behavior among adolescents and accounted for $42 \%$ of the variance in behavior change (13). Employees' beliefs regarding the outcomes of proper food safety behavior might influence how they adhere to proper practices $(37,65)$. Therefore, the aim of this study was to determine whether selfefficacy, self-regulation, outcome expectations, and environmental determinants, as constructs of the SCT, are predictive of self-reported food safety behaviors directly and indirectly through behavioral intentions of food handlers in independent ethnic restaurants. Figure 1 shows the conceptual research model. Accordingly, the following hypotheses were proposed:

$\mathrm{H}_{1}$ : Self-efficacy is predictive of food safety behavioral intentions.

$\mathrm{H}_{2}$ : Environmental determinants are predictive of food safety behavioral intentions.

$\mathrm{H}_{3}$ : Outcome expectations are predictive of food safety behavioral intentions.

$\mathrm{H}_{4}$ : Self-regulation is predictive of food safety behavioral intentions.

$\mathrm{H}_{5}$ : Self-reported food safety behaviors are mediated by food safety behavioral intentions.

\section{MATERIALS AND METHODS}

\section{Study design and sampling}

This study followed a sequential mixed-method approach, using focus group interviews to inform the design of a survey to be used for the main study. A multi-stage random sampling technique was utilized to collect data for the main study. The data was collected on site, and restaurants were drawn from three counties in a Midwestern state. These counties were selected because they have the largest number of independent Mexican and Chinese restaurants in Kansas (23). Independent ethnic restaurants were defined as independently owned restaurants that serve foods in a host country representing a heritage and culture of an ethnic group (42).

A list of commercial foodservice establishments licensed to sell food was obtained from the licensing body in the state (23). All chain restaurants were purged from the list, 


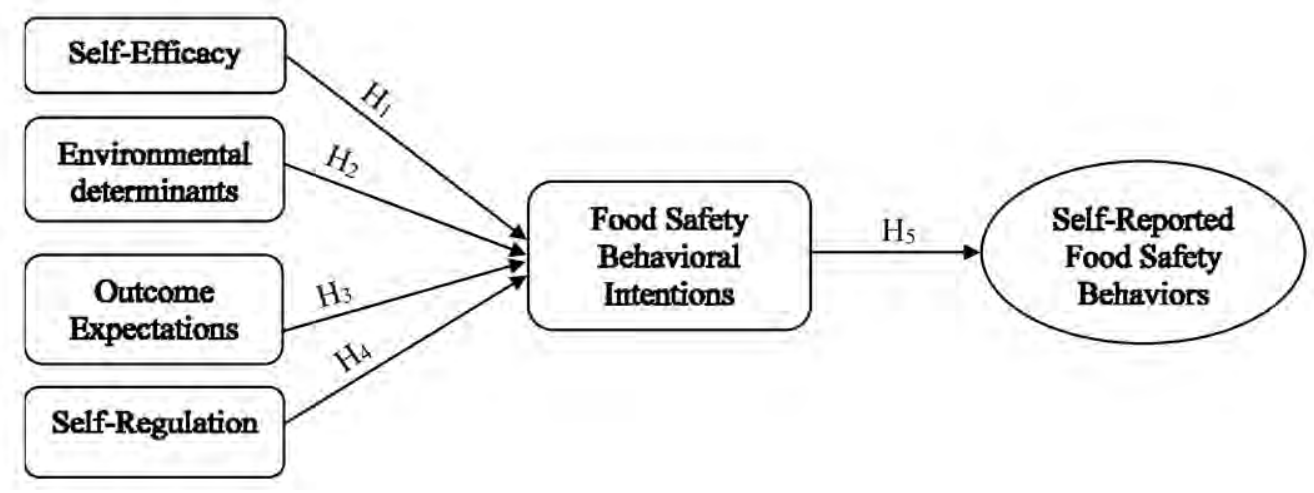

FIGURE 1. Conceptual research model using the social cognitive theory.

yielding 555 independent ethnic restaurants. Only Chinese and Mexican restaurants were selected, because they are among the most popular ethnic restaurants in the U.S. $(3,45)$. There were 119 independent Chinese restaurants and 176 independent Mexican restaurants in the refined list. Restaurants were at first identified as either Chinese or Mexican by name. Further cross-checking was done on the website of each restaurant to ensure that it was an independent Chinese or Mexican restaurant. To ensure consistency, Chinese or Mexican restaurants that operate in hotels, grocery stores, or clubs were excluded. Any independent Chinese or Mexican restaurant from which employees were selected for the focus group interviews or the pilot study were removed from the database prior to selecting the final sample. The sample estimated to achieve a $95 \%$ confidence interval based on the number of constructs under investigation was 138 food handlers, according to results obtained by use of $G^{*}$ Power (Version 3); however, in order to check for the measurement scales' validity, 250 food handlers were targeted.

\section{Survey design}

It has been recommended that a focus group have six to eight participants, but not more than ten $(40,55)$. For the purpose of designing the questionnaire, three focus group interviews with food handlers from independent Chinese and Mexican restaurants were planned, with the goal of having a minimum of six participants in each group. Because of employees' time constraints and difficulty of recruitment, conducting three focus groups was not feasible. Therefore, one focus group interview was conducted with seven food handlers from an independent Mexican restaurant. In addition, four focus group interviews, each with two or three participants, were conducted, for a total of ten food handlers from independent Mexican and Chinese restaurants. All interviews followed a questioning route with open-ended questions and other probe questions if required. The questioning route was prepared by the researcher based on previous research $(1,12,19,37,53,59,73)$

All interviews were audiorecorded, transcribed, and coded and with use of a thematic codes list that included both pre-established and free codes. To ensure reliability and intercoder agreement (20), another researcher was asked to independently transcribe and code the recordings. Coding themes were then examined, and any disagreement was resolved. The coded data was analyzed using the procedures of NVivo 12 Plus for Windows (Version 12). Analysis of the interviews' responses showed nine main themes: self-efficacy, self-regulation, environmental factors, outcome expectations, behavioral intentions, food safety behaviors, cultural background, attitude, and knowledge.

The results of the interviews were used to generate an item pool for the measurement scales in the questionnaire. The most frequently discussed thematic items identified from the transcripts, along with other items adapted from the literature, were developed into 55 statements in a Likert format on a scale of 1 to 5. For example, selfefficacy included ten items to measure the participants' level of confidence about their ability to perform the three investigated behaviors. Self-efficacy items were phrased using language similar to that used by the interviewees, such as the scale item "constantly prepare food in a sanitary manner, even when I am busy with other tasks." Similarly, the sub-themes of the environmental factors were used to build up the items in the environmental determinants scale. For instance, the sub-theme time constraints was developed into the scale item "I get sufficient time to work in a hygienic and safe food way." The sub-themes of outcome expectations regarding the advantages and disadvantages of performing proper food safety behaviors were also used in the outcome expectations scale. For example, reducing the risk of foodborne illnesses, avoiding lawsuits, and maintaining a good reputation were sub-themes that were incorporated 
into scale items such as "I will help protect my restaurant from liability for foodborne illnesses" and "I will help protect the reputation of my restaurant."

The questionnaire (as shown in the appendix) consisted of six subscales to measure the four constructs of the SCT, food safety behavioral intentions, and self-reported food safety behaviors. Eleven demographic and operational information items were included to describe and understand the sample. The self-efficacy scale included 10 items using a 5-point Likert-type scale $(1=$ cannot do at all to $5=$ can do for sure $)$ adapted with modifications $(16,17)$. The environmental determinants scale included 10 items measured on a 5-point Likert scale ( $1=$ strongly disagree to $5=$ strongly agree $)$ adapted from (2) and (21).

The outcome expectations scale included eight items measured on a 5-point Likert scale ( $1=$ strongly disagree to $5=$ strongly agree), adapted with modification (69). The outcome expectations items included social, physical, and self-evaluative consequences of the behavior (10).

The self-regulation scale consisted of three subscales, selfmonitoring, goal setting, and self-evaluation (8). The three subscales were measured with three items, each on a 5-point Likert scale ( $1=$ strongly disagree to $5=$ strongly agree $)$ adapted with modification (66).

Food safety behavioral intentions were measured with six items on a 5-point Likert scale ( $1=$ strongly disagree to $5=$ strongly agree) adapted from (36) and (46). Twelve items were used to measure self-reported food safety behavior, using a frequency response scale $(1=$ never to $5=$ always $)$ adapted from (60) and (73). The food safety behavior scale focused on three food safety behaviors implicated in recurring incidents of foodborne illnesses in restaurants: handwashing, use of a thermometer, and proper handling of food and work surfaces $(37,59,70,73)$.

Different descriptors/anchors were used in the 5-point scales throughout the questionnaire to mitigate the potential impact of common method bias associated with the crosssectional self-reporting method used and to alleviate potential social desirability bias caused by commonalities in scale endpoints (61). In addition, anonymity of respondents and their answers were assured to reduce the effect of evaluation apprehension.

The questionnaire was translated to Chinese and Spanish, and back translated to English to ensure that the correct wording was used. To assess content validity, an experienced researcher in food safety behavior reviewed the questionnaire for face validity and adequacy of the scales' content. The research protocol (proposal number: 9170) was approved by the Kansas State University Institutional Review Board prior to data collection.

\section{Data collection}

The questionnaire was pilot tested with a sample of 25 food handlers from independent Chinese and Mexican restaurants prior to data collection. Restaurant owners/managers were contacted in person to request the participation of their employees. After owners' /managers' approval had been received, the questionnaire was administered onsite to employees who wished to participate. Each participant who completed the pilot test received $\$ 5$ as a token of appreciation. No major issues were noted during the pilot testing, although minor modifications to a few questions were made. For instance, unnecessary spaces between questions were adjusted to reduce the number of pages, thus reducing the fatigue caused by participants completing long questionnaires. In addition, item $\mathrm{D}$ in the question about participants' level of education in the Spanish version was changed from "Algo de universidad" to "Algunas clases universitarias," which means completing some college-level classes and is more consistent with the English version. Reliability of the measurement scales was initially determined during pilot testing and then was verified after the final data was collected.

The main study consisted of 50 restaurants from the three counties included in the study, with the goal of sampling five food handlers randomly from each of the 50 restaurants. If a selected restaurant owner/manager declined the request for participation of the restaurant's food handlers, a replacement was taken from another independent Chinese or Mexican restaurant in the counties until the target number of participants was obtained. To ensure consistency, participants were chosen based on two selection criteria: participants had to be at least 18 years of age at the time of recruitment and had to be food handlers.

Each employee received a cover letter that included information about the study. Participants who completed the questionnaire after having read the letter of information were presumed to have given informed consent. Each participant who completed the questionnaire received $\$ 5$ as a token of appreciation for their participation in the survey.

\section{Data analysis}

Data was analyzed using SPSS for Windows (Version 25). Cronbach's alpha coefficient was computed to determine the internal consistency/reliability for each scale. A cutoff point of 0.70 was used to demonstrate consistency (58). Frequencies, means, and standard deviations were computed to summarize and screen the data. Multiple regression analysis was used to examine the ways in which the constructs act alone and together to influence behavioral intentions and self-reported food safety behaviors. Mediation analysis was performed using the procedures of the PROCESS macro developed for SPSS (35), including bootstrap confidence intervals to examine the indirect effect of food safety behavioral intentions. All significance levels were set at $P<0.05$. Confirmatory factor analysis (CFA) was conducted using AMOS for Windows (Version 25) to test the constructs' validity in the proposed model. 


\section{TABLE 1. Demographics of respondents and their operational information (N = 201)}

\begin{tabular}{|c|c|c|c|c|c|}
\hline Characteristic & Frequency $^{a}$ & Percentage & Characteristic & Frequency ${ }^{a}$ & Percentage \\
\hline \multicolumn{3}{|l|}{ Gender } & \multicolumn{3}{|l|}{ Restaurant Ownership } \\
\hline Male & 113 & 56.2 & Independent & 66 & 100 \\
\hline Female & 85 & 42.3 & \multicolumn{3}{|l|}{ Restaurant Theme } \\
\hline \multicolumn{3}{|l|}{ Ethnicity } & Mexican & 44 & 66.7 \\
\hline Hispanic or Latino & 103 & 51.2 & Chinese & 22 & 33.3 \\
\hline Asian & 75 & 37.3 & \multicolumn{3}{|l|}{ Type of Service } \\
\hline Caucasian & 13 & 6.5 & Casual dining & 26 & 39.4 \\
\hline Native American & 5 & 2.5 & Quick casual & 20 & 30.3 \\
\hline African American & 2 & 1 & Buffet & 10 & 15.2 \\
\hline Other & 3 & 1.5 & Quick service (Fast food) & 9 & 13.6 \\
\hline \multicolumn{3}{|l|}{ Education } & Fine dining & 1 & 1.5 \\
\hline Less than high school & 34 & 16.9 & \multicolumn{3}{|l|}{ Food Safety Training } \\
\hline High school/GED & 75 & 37.3 & Yes & 130 & 64.7 \\
\hline Associate degree & 25 & 12.4 & No & 71 & 35.3 \\
\hline Some college & 34 & 16.9 & \multicolumn{3}{|l|}{ Food Safety Certification } \\
\hline Bachelor's degree & 28 & 13.9 & No & 116 & 57.7 \\
\hline Graduate degree & 4 & 2 & Yes & 80 & 39.8 \\
\hline \multicolumn{3}{|l|}{ Position } & & & \\
\hline Line cook & 70 & 34.8 & & & \\
\hline Prep cook & 58 & 28.9 & & & \\
\hline Other & 54 & 26.9 & & & \\
\hline Executive chef & 17 & 8.5 & & & \\
\hline \multicolumn{3}{|l|}{ Years of Experience } & & & \\
\hline 5 years or less & 86 & 42.8 & & & \\
\hline $6-15$ years & 72 & 35.8 & & & \\
\hline $16-25$ years & 24 & 11.9 & & & \\
\hline 26 years or more & 19 & 9.5 & & & \\
\hline
\end{tabular}

Note. ${ }^{a}$ Responses may not equal 201 due to non-response to an item.

\section{RESULTS}

\section{Respondents' profile}

A total of 250 questionnaires were distributed onsite, and 204 participants from 66 independent Chinese and Mexican restaurants agreed to participate, with a range of one to five participants from each restaurant. Because of incomplete data or responses from non-food handlers, only 201 responses were usable. Respondents' characteristics and operational data are presented in Table 1. Although the number of responses gathered was less than the target of 250 because of limitations of time and financial resources, this was an adequate amount of data to achieve the $95 \%$ confidence interval calculated by $\mathrm{G}^{*}$ Power (Version 3 ).

\section{Descriptive statistics, reliability, and constructs validity}

Table 2 presents the means, standard deviations, and reliability coefficients for the measures.

The measurement scales demonstrated acceptable levels of reliability, which exceeded the cutoff point of 0.70 (58). The self-efficacy scale mean score was $4.59 \pm 0.41$, indicating that respondents had relatively high self-efficacy regarding confidence in their ability to perform handwashing, use of thermometer, and proper handling of food and work surfaces. The item "use the thermometer at the completion of reheating food to $165^{\circ} \mathrm{F}^{\prime \prime}$ had the lowest mean score $(4.46 \pm 0.66)$. The composite mean score for self-regulation was $4.56 \pm 0.35$, 


\section{TABLE 2. Means, standard deviations, and reliability of measurement scales}

Scale Items

Mean

Std.

Deviation

Self-Efficacy $(\alpha=0.85)$

Clean and sanitize food contact surfaces before and after preparing food.

Constantly prepare food in a sanitary manner, even when I am busy with other tasks.

Wash my hands when food preparation tasks are interrupted or changed.

Correctly use a thermometer to determine if food is cooked to a safe temperature.

Use the thermometer to ensure proper food holding temperature.

Use the thermometer at the completion of reheating food to $165^{\circ} \mathrm{F}$.

Composite Score

\begin{tabular}{|l|l}
\hline 4.72 & 0.40 \\
\hline 4.67 & 0.47 \\
\hline 4.65 & 0.47 \\
\hline 4.50 & 0.64 \\
\hline 4.51 & 0.58 \\
\hline 4.46 & 0.66 \\
\hline 4.59 & $\mathbf{0 . 4 1}$ \\
\hline
\end{tabular}

Self-Regulation $(\alpha=0.87)$

I have a goal to ensure food has reached a safe temperature for service and consumption.

I monitor my own handling practices of food and work surfaces.

I evaluate my handwashing practices to ensure I follow the proper steps.

I closely monitor my handwashing practices during my shift.

I always set a goal to ensure food safety when handling food and work surfaces.

I always evaluate my own handling practices of food and work surfaces.

I monitor my thermometer use practices to ensure food safety.

I evaluate myself when I use a food thermometer.

Composite Score

Environmental Determinants $(\alpha=0.90)$

The necessary infrastructure and equipment (e.g., handwashing sinks) are available and accessible to support food safety.

My manager/supervisor enforces food safety rules consistently with employees.

My manager/supervisor is actively involved to ensure safe food handling is practiced.

My manager/supervisor inspires me to follow proper food safety practices.

Facilities are adequately equipped to follow safe food handling practices.

Procedures and instructions concerning food safety are provided to me.

My coworkers are always supportive of each other regarding food safety.

Sufficient education and food safety training are provided.

I get sufficient time to work in a hygienic and safe food way.

Sufficient financial resources are provided to support hygiene and food safety.

Composite Score

\begin{tabular}{l|l|l}
\hline 4.67 & 0.42 \\
\hline 4.67 & 0.38 \\
\hline 4.65 & 0.41 \\
\hline 4.58 & 0.47 \\
\hline 4.55 & 0.48 \\
\hline 4.54 & 0.46 \\
\hline 4.45 & 0.58 \\
\hline 4.40 & 0.60 \\
\hline 4.56 & $\mathbf{0 . 3 5}$ \\
\hline
\end{tabular}

Behavioral Intentions $(\alpha=0.86)$

I am willing to separate raw food from ready-to-eat food during preparation.

I am willing to clean and sanitize food contact surfaces between each use.

I plan to wash my hands whenever it is required.

I intend to use a food thermometer to check the temperature on the hot line/cold line.

\begin{tabular}{|l|l}
\hline 4.73 & 0.34 \\
\hline 4.67 & 0.41 \\
\hline 4.66 & 0.39 \\
\hline 4.61 & 0.48 \\
\hline 4.61 & 0.44 \\
\hline 4.60 & 0.46 \\
\hline 4.58 & 0.48 \\
\hline 4.53 & 0.49 \\
\hline 4.51 & 0.52 \\
\hline 4.50 & 0.54 \\
\hline 4.65 & $\mathbf{0 . 4 5}$ \\
\hline
\end{tabular}

\begin{tabular}{|l|l|}
\hline 4.79 & 0.30 \\
\hline 4.73 & 0.36 \\
\hline 4.66 & 0.46 \\
\hline 4.55 & 0.51 \\
\hline
\end{tabular}

Continued on next page. 


\section{TABLE 2. Means, standard deviations, and reliability of measurement scales (cont.)}

\section{Scale Items}

Mean

Std.

Deviation

Behavioral Intentions $(\alpha=0.86)$

\begin{tabular}{l|c|c}
\hline I plan to use a food thermometer at the completion of reheating food. & 4.51 & 0.53 \\
\hline I intend to use a food thermometer at the completion of cooking. & 4.45 & 0.58 \\
\hline Composite Score & $\mathbf{4 . 6 2}$ & $\mathbf{0 . 3 6}$ \\
\hline
\end{tabular}

Outcome Expectations $(\alpha=0.72)$

\begin{tabular}{l|c|c}
\hline I will help protect my restaurant from liability for foodborne illnesses. & 4.75 & 0.35 \\
\hline Customers will be satisfied. & 4.65 & 0.43 \\
\hline I will feel a sense of accomplishment. & 4.59 & 0.48 \\
\hline My manager/supervisor will praise my performance. & 4.38 & 0.62 \\
\hline Composite Score & 4.59 & $\mathbf{0}$ \\
\hline
\end{tabular}

Self-Reported Food Safety Behaviors $(\alpha=0.88)$

\begin{tabular}{l|c|c}
\hline I wash my hands after sneezing, coughing, or using a tissue. & 4.85 & 0.23 \\
\hline I wash my hands when starting shift. & 4.78 & 0.31 \\
\hline I wash, rinse, and sanitize food contact surfaces between working with different types of food or ingredients. & 4.75 & 0.32 \\
\hline I wash my hands before putting on or changing gloves. & 4.61 & 0.46 \\
\hline I use a thermometer to ensure that hot food is held at $135^{\circ} \mathrm{F}$ or higher and cold food is held at $41^{\circ} \mathrm{F}$ or less. & 4.60 & 0.50 \\
\hline $\begin{array}{l}\text { I check the internal temperature of food by inserting the thermometer's probe into the thickest part } \\
\text { of the product. }\end{array}$ & 4.50 & 0.59 \\
\hline $\begin{array}{l}\text { I use a thermometer to check the temperature of food at the completion of cooking. } \\
\text { I use a thermometer to check the temperature of food at the completion of reheating. }\end{array}$ & 4.46 & 0.61 \\
\hline Composite Score & 4.42 & 0.66 \\
\hline
\end{tabular}

suggesting that respondents had good practices related to self-monitoring, self-evaluation, and goal setting to ensure food safety. The item "I evaluate myself when I use a food thermometer" had the lowest mean score $(4.40 \pm 0.60)$.

Environmental determinants had a composite mean score of $4.65 \pm 0.45$. The item "necessary infrastructure and equipment (e.g., handwashing sinks) are available and accessible to support food safety" had the highest mean score $(4.73 \pm 0.34)$ and the item "Sufficient financial resources are provided to support hygiene and food safety" had the lowest mean score $(4.50 \pm 0.54)$.

The construct of outcome expectations had a composite mean score of $4.59 \pm 0.35$, with the highest mean score for the item "I will help protect my restaurant from liability for foodborne illnesses" $(4.75 \pm 0.35)$ and the lowest mean score for the item "my manager/supervisor will praise my performance" $(4.38 \pm 0.62)$.
The composite mean score of the food safety behavioral intentions construct was $4.62 \pm 0.36$. The highest mean score was for the item "I am willing to separate raw food from ready-to-eat food during preparation" (4.79 \pm 0.30$)$ and the lowest mean score was for the item "I intend to use a food thermometer at the completion of cooking" (4.45 \pm 0.58$)$.

The composite mean score for self-reported food safety behaviors was $4.62 \pm 0.36$. The items "I wash my hands after sneezing, coughing, or using a tissue" and "I wash my hands before and after handling raw food" had the highest mean score, $4.85 \pm 0.23$ and $4.84 \pm 0.25$, respectively. The items "I use a thermometer to check the temperature of food at the completion of cooking" and "I use a thermometer to check the temperature of food at the completion of reheating" had the lowest mean scores, $4.46 \pm 0.61$ and $4.42 \pm 0.66$, respectively.

The initial results of CFA showed a weak fit of the model to the data $\chi^{2} / \mathrm{df}=2.53, \mathrm{GFI}=0.58, \mathrm{CFI}=0.69, \mathrm{NFI}=0.58, \mathrm{IFI}$ $=0.69$, and RMSEA $=0.08$. However, the standardized factor 


\section{TABLE 3. Problematic items removed from the measurement scales}

Scale Items Removed

\begin{tabular}{l}
\hline Self-Efficacy \\
\hline Item \# 3 Wash my hands with soap and water for 20 seconds before I begin to prepare food \\
\hline Item \# 5 Perform proper food handling practices to prevent cross-contamination \\
\hline Item \# 6 Wash my hands before putting on or changing gloves \\
\hline Item \# 8 Wash my hands after using the restroom, coughing, sneezing, smoking, or touching body parts \\
\hline Self-Regulation \\
\hline Item \# 15 I wash my hands with a goal to ensure food safety \\
Outcome Expectations \\
\hline Item \# 38 I will not be able to focus on primary tasks of preparation and cooking \\
\hline Item \# 40 I will reduce the risk of foodborne illnesses \\
\hline Item \# 42 I will help protect the reputation of my restaurant \\
\hline Item \# 43 I will avoid losing my job \\
\hline Self-Reported Food Safety Behaviors \\
\hline Item \# 47 I wash my hands before and after handling raw food \\
\hline Item \# 48 I wash my hands after touching anything that may contaminate hands (chemicals, non-sanitized work surfaces, body parts) \\
\hline Item \# 50 I cover and label food properly before storing or holding \\
\hline Item \# 51 I separate raw products from ready-to-eat products when preparing food
\end{tabular}

loadings, the modification indices, and the standardized residuals suggested that a better fit could be obtained by excluding problematic items with standardized factor loadings less than 0.50 and had more error variance than explained variance (33). The items with low standardized factor loadings included four items from the self-efficacy scale, one item from the self-regulation scale, four items from the outcome expectations scale, and four items from the self-reported food safety behaviors scale as shown in Table 3. The goodness-of-fit indices for the hypothesized model after removing the problematic items are presented in Table 4.

Although the model fit indices did not meet the cutoff values proposed (38), it has been suggested that these cutoff points are guides for usage, not absolute criteria, and they should be considered in line with the model itself, the sample, and the research context to establish what is an acceptable model (33). To verify the fit of the hypothesized model, bootstrap confidence intervals of 5,000 samples were computed, and the results indicated that the model fit in 4,548 out of the 5,000 bootstrap samples, with $P<0.05$ for all standardized regression weights of the model constructs. In addition, the Bollen-Stine bootstrapping procedure (15) was used to test the null hypothesis that the model is correct. The result showed that the null hypothesis was not rejected $(P=0.09)$, indicating that the model fits.

\section{Hypotheses testing results}

A multiple regression analysis was conducted to test hypotheses $1,2,3$, and 4, related to whether self-efficacy, environmental determinants, outcome expectations, and self-regulation are predictive of food safety behavioral intentions. Mediation analysis was performed to test Hypothesis 5, related to whether food safety behavioral intentions mediate the relationship between the four constructs of the SCT and self-reported food safety behaviors. Table 5 shows the multiple regression results for predicting food safety behavioral intentions. The resulting model was significant $(\mathrm{F}=75.246$, $P=0.002$ ) in predicting food safety behavioral intention.

The findings of regression analysis showed that self-efficacy was not a significant predictor of food safety behavioral intentions $(\beta=0.078, P=0.219)$. Therefore, hypothesis 1 was not supported. The results also indicated that environmental determinants, including both physical and social factors, significantly predicted food safety behavioral intentions $(\beta=0.181, P=0.011)$. Thus, hypothesis 2 was supported. The results also showed that outcome expectations, represented in the respondents' beliefs about anticipated outcomes of carrying out a behavior, significantly influenced their food safety behavioral intentions $(\beta=0.152$, $P=0.018$ ). Therefore, hypothesis 3 was supported. The findings indicated that self-regulation is significantly predictive 


\section{TABLE 4. Goodness-of-fit indices for the hypothesized model}

\begin{tabular}{l|c|c|c|c|c|c}
\hline CFA Results & $\chi^{2} / d f$ & CFI $^{\mathbf{a}}$ & GFI $^{\mathbf{b}}$ & IFI $^{\mathbf{c}}$ & RMSEA $^{\mathrm{d}}$ & NFI $^{\mathbf{e}}$ \\
\hline Measurement & 2.24 & 0.83 & 0.73 & 0.83 & 0.07 & 0.73 \\
\hline
\end{tabular}

Note. $\mathrm{N}=201$.

${ }^{\mathrm{a}} \mathrm{CFI}=$ comparative fit index.

${ }^{\mathrm{b}} \mathrm{GFI}=$ goodness of fit index.

'IFI $=$ incremental fit index.

${ }^{\mathrm{d}} \mathrm{RMSEA}=$ root mean square error of approximation.

${ }^{\mathrm{e}} \mathrm{NFI}=$ normed fit index.

\section{TABLE 5. Multiple regression model for predicting food safety behavioral intentions}

\begin{tabular}{|c|c|c|c|c|c|}
\hline Model & Sum of Squares & df & Mean Square & F & Sig. \\
\hline Regression & 15.663 & 4 & 3.916 & 75.246 & $0.002^{*}$ \\
\hline Residual & 10.200 & 196 & 0.052 & & \\
\hline Total & 25.863 & 200 & & & \\
\hline
\end{tabular}

\begin{tabular}{|c|c|c|c|c|c|}
\hline & $\begin{array}{l}\text { Unstandardized } \\
\text { Coefficients }\end{array}$ & $\begin{array}{c}\text { Standardized } \\
\text { Coefficients }\end{array}$ & & & \\
\hline Model & $b$ & $S E B$ & $\beta$ & $t$ & Sig. \\
\hline Constant & 0.757 & 0.233 & & 3.244 & 0.001 \\
\hline Self-efficacy & 0.067 & 0.055 & 0.078 & 1.233 & 0.219 \\
\hline Self-regulation & 0.477 & 0.079 & 0.467 & 6.048 & $0.001^{*}$ \\
\hline Environmental determinants & 0.143 & 0.056 & 0.180 & 2.567 & $0.011^{*}$ \\
\hline Outcome Expectations & 0.154 & 0.064 & 0.152 & 2.392 & $0.018^{*}$ \\
\hline
\end{tabular}

Note: ${ }^{*} P<0.05$

of food safety behavioral intentions $(\beta=0.467, P=0.001)$. Therefore, hypothesis 4 was supported.

Figure 2 illustrates the standardized regression coefficients for the relationship between the predictors and self-reported food safety behaviors mediated by food safety behavioral intentions. The results of mediation analysis showed that behavioral intentions significantly mediate the relationships between self-efficacy and self-reported food safety behaviors ( $b=0.24,95 \%$ CI $[0.161,0.336]$, self-regulation and selfreported food safety behaviors $(b=0.252,95 \%$ CI $[0.155$, $0.366]$ ), outcome expectations and self-reported food safety behaviors $(b=0.355,95 \%$ CI $[0.247,0.469])$, and environmental determinants and self-reported food safety behaviors $(b=0.269,95 \%$ CI $[0.172,0.393])$. Therefore, Hypothesis 5 was supported.

\section{DISCUSSION}

When self-efficacy and self-regulation are explored together, respondents scored low in both regarding the use of a thermometer. This result is consistent with a study that found that food thermometers are seldom used by food handlers in independent Chinese restaurants (43). Although the results of the current study showed that food handlers had high self-efficacy and self-regulation, the influence of their cultural traditions of food preparation is inevitable and can mingle with the business culture (29). Previous 


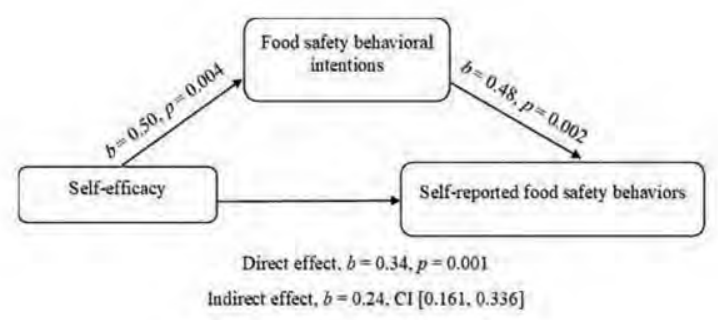

(a)

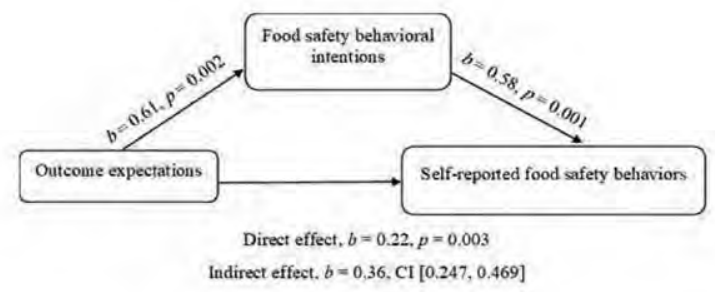

(c)

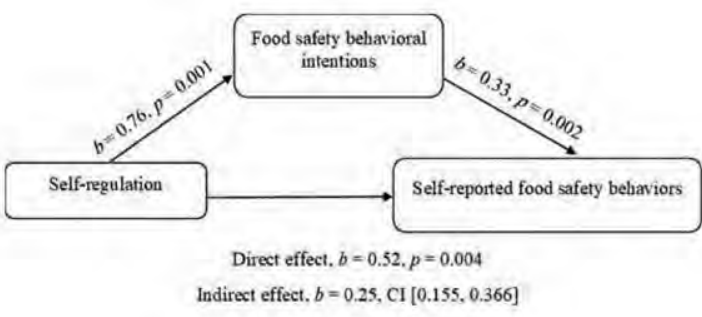

(b)

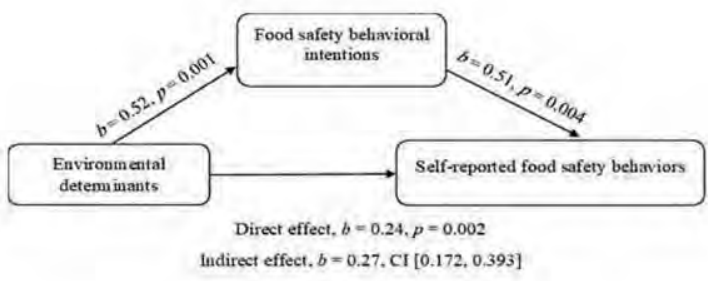

(d)

FIGURE 2. Models of self-efficacy (a), self-regulation (b), outcome expectations (c), and environmental determinants (d) as predictors of self-reported food safety behaviors mediated by food safety behaviroal intentions.

research indicated that cultural traditions of foodservice employees in ethnic restaurants influence the extent to which standard food safety practices are followed (34).

The lowest mean score for the environmental determinants was related to sufficiency of financial resources to support hygiene and food safety. This result verified the importance of providing appropriate equipment and supplies for following proper food safety practices and highlighted the lack of financial resources allocated to support food safety in small independent ethnic restaurants. Similarly, a previous study indicated that the nature of most independent ethnic restaurants as small-scale businesses with limited resources could affect efforts to improve food safety (50). This result is also consistent with several studies that showed that lack of financial resources was a barrier to improving food safety in independent ethnic restaurants $(27,49,56)$.

The highest mean score for the construct of outcome expectations was for the item related to protecting restaurants from liability for foodborne illnesses. This result suggested that respondents perceived protecting their operations from liability as the most important positive outcome of performing proper handwashing, handling of food and work surfaces, and use of a thermometer. The SCT posits that a behavior can be affected by one's anticipation of how they will feel about themselves if they do or do not perform that behavior (52). Thus, educating food handlers about the positive outcomes of performing food safety behaviors would act as an incentive to follow proper food safety practices to protect themselves and their operation from liability.

The composite mean score result of the food safety behavioral intentions construct suggested that respondents had high intention of performing proper handling of food and less intention to use a food thermometer. This may be attributed to employees' cultural influence, which caused them to use their own methods to check the doneness of foods, or to having less time to check the temperature of food. Similarly, in a previous study using a seven-point Likert scale to measure behavioral intention, it was found that foodservice employees in the investigated restaurants had less intention to use a thermometer $(6.20 \pm 1.16)$, compared with sanitizing surfaces $(6.57 \pm 1.16)$ and handwashing $(6.48 \pm$ 0.96) (59).

Although the results of this study showed that food handlers had high self-efficacy and self-regulation and scored favorably in all behaviors, they scored low in the use of a thermometer at the completion of cooking and reheating. This could be attributed to lack of motivation, lack of risk perception, lack of time, and/or unavailability of food thermometers (48). In a study that investigated selfreported and observed food handling behaviors of Hispanic food handlers in a home setting, the researchers found that $47 \%$ of participants reported being confident of their own method for determining cooking doneness, and $28 \%$ of them mentioned that inability to use a thermometer was a reason for not using it (22). 
The results of regression analysis of the relationship between self-efficacy, self-regulation, environmental determinants, and outcome expectations as predictors and self-reported food safety behaviors as a dependent variable indicated that self-efficacy was a significant predictor of self-reported food safety behaviors $(\beta=0.275, P=0.003)$. This finding suggested that employees' high level of selfefficacy could be translated directly to positive self-reported food safety behaviors. A study investigated the relationship between adolescents' self-efficacy and their food safety behavioral change across three administrations of educational interventions. The researchers found that self-efficacy was the only significant predictor of behavior change $(\beta=0.421$, $P<0.001$ ) (13). Previous research has also found that individuals' perception of self-efficacy accounts for the level of effort and persistence to perform a specific behavior (39, 54). Thus, it is evident that self-efficacy can directly influence a person's behavior and does not necessarily induce their behavioral intentions.

On one hand, the results of regression analysis confirmed the importance of adequacy of necessary equipment and access to resources for following safe food handling practices in the investigated restaurants. On the other hand, this finding suggested that lack of necessary infrastructure and equipment could hinder food handlers from performing proper food safety behaviors. For instance, in a study that investigated restaurant employees' beliefs about food safety, the researchers found that lack of access to resources was among the most frequently reported barriers to handwashing, use of a thermometer, and proper handling of food and contact surfaces (69). Another study also found that lack of supplies such as gloves and alcohol wipes was a major barrier to performing proper food safety behaviors (68). The finding also suggested the importance of social support represented in the role that managers/supervisors can play in motivating their employees to follow proper food safety behaviors. Managers can support proper food safety behaviors by acting as role models and giving their employees verbal reminders and praise for following proper practices (37). Thus, interventions aimed at increasing food handlers' intentions to follow proper food safety practices may take advantage of focusing on increasing social support from peers and managers. This will help foster confidence in those who feel they are ill equipped to perform behaviors properly (25).

The finding of regression analysis regarding outcome expectations suggested that the more a food handler feels their food safety behaviors are self-rewarding, in terms of feeling a sense of accomplishment, the greater their intention will be to adhere to proper food safety behaviors. A previous study that investigated perceived risks and risk communication behaviors of restaurant servers was related to serving customers with food allergy. The researchers found that perceived severity of food allergy reactions was a significant predictor of restaurant servers' allergy risk reduction and communication behaviors $(\beta=0.133, P<$ 0.001 ) (71). Therefore, educating food handlers on the consequences of improper food safety behaviors, using persuasive messages, is an important step in improving their behaviors (37).

The findings of regression analysis of the relationship between self-regulation and food safety behavioral intentions implied that food handlers who reported monitoring their food safety practices, setting goals, and evaluating their performance were more likely to have a sustained intention to perform proper behaviors and are consistent with the views of Bandura (11). Thus, the more food handlers engage in self-regulation, the more they will be able to self-control their behavior, especially if they perform it in a supportive environment (31). This finding also suggested that self-regulation might create motivational influence on the formation of food handlers' intentions to follow safe food handling behaviors.

Although this study focused on the social-cognitive facets of self-regulation, previous research that investigated the neurocognitive differences between people in their ability to self-regulate their behaviors reported similar results. For instance, a study investigated the addition of self-regulation as a variable to the Theory of Planned Behavior in explaining exercise and diet behaviors. The researchers found that individual differences in neurocognitive self-regulation represented in executive function or operations of the brain that control a behavior explained $59 \%$ of the variance in exercise behavior and $61 \%$ of the variance in diet behavior (32).

The findings of mediation analysis were consistent with the view of Bandura (7) that most behaviors are mediated by behavioral intentions. These findings suggested that food handlers' intention to perform food safety behaviors can lead to better compliance with the behaviors when self-efficacy, self-regulation, outcome expectations, and environmental determinants are favorable to the behaviors. Similarly, it was found that self-efficacy had a strong indirect effect on water conservation behavior through behavioral intentions $(\beta=0.22)$ and outcome expectations had a moderate indirect effect on the behavior $(\beta=0.13)$ (72). Therefore, building up employees' confidence with regard to performing the behaviors (24), providing adequate resources and reminders to the employees to perform the behaviors, stressing that bosses, coworkers, customers, and health inspectors want them to follow proper food safety practices (59), and encouraging employees to regulate themselves can increase their intention to consequently engage in proper food safety behaviors.

\section{CONCLUSIONS}

This study used the constructs of the Social Cognitive Theory to predict self-reported food safety behaviors in independent Chinese and Mexican restaurants. Few studies 
have used the Social Cognitive Theory in the commercial foodservice setting. This study is among the first attempts to develop a scale to measure the constructs of the Social Cognitive Theory in this setting. The developed scale may encourage future studies to advance the theory and yield theoretical and practical implications to improve food safety behaviors in different settings in the foodservice industry. The hypothesized model in this study was significant in predicting food safety behavioral intentions $(\mathrm{F}=75.246$, $P=0.002)$ and explained about $60.6 \%$ of the variance in food safety behavioral intentions. This was comparable to the results of a similar study using the constructs of the Social Cognitive Theory (67).

\section{Implications}

The results of this study can be used by public health officials and food safety professionals to help owners, managers, and supervisors identify better ways to communicate information about positive food safety practices with food handlers in independent ethnic restaurants. Unlike non-ethnic restaurants, an ethnic restaurant is a unique environment where employees' ethnic culture mingles with the business culture. This is particularly true because most independent ethnic restaurants are family-owned and family-operated businesses (3). The results of this study would help guide the understanding of the social cognitive factors that influence food safety behaviors in these operations. The following are recommendations for operators of independent Chinese and Mexican restaurants and public health officials, based on the results of this study:

- Owners, managers, and supervisors should educate their food handlers on the consequences of improper food safety behaviors by using persuasive messages to improve their behaviors or to motivate them to continue to perform proper food safety behaviors. These messages can be expressed verbally or in the form of posters in the spoken language of the food handlers.

- Operators and managers should focus on increasing social support among employees to prepare food safely and build up confidence in those who feel they are ill equipped to perform food safety behaviors properly.

- Operators in independent ethnic restaurants need to support food handlers' self-efficacy by telling the person that he or she can perform the proper behavior. Consistent encouragement can reinforce confidence to bring about more efforts toward improving food safety behaviors. Also, observing managers, supervisors, and coworkers performing successfully can increase self-efficacy.
- Operators of independent ethnic restaurants should motivate their food handlers to follow selfregulation strategies such as monitoring their food safety practices, setting goals, and evaluating their performance to gain a sustained intention to perform proper behaviors over time.

- Public health officials and developers of educational interventions and training programs should consider targeting food handlers' self-efficacy, self-regulation, outcome expectations, and environmental determinants in the workplace that influence food safety behaviors when developing training materials.

\section{Limitations and recommendations for future research}

This study has some limitations. First, the sample consisted of food handlers in independent Chinese and Mexican restaurants in three counties in Kansas. Therefore, the results cannot be generalized to other independent ethnic restaurants and other foodservice operations. It would be important for future studies to replicate the study in other foodservice settings and involve other employees, such as servers, who might influence food safety.

The role of ethnicity was not examined in this study because of the lack of ethnic diversity in the study sample. Future studies utilizing a sample that represents a wider range of ethnic backgrounds are encouraged and would be more effective at measuring potential differences in food safety behaviors based on ethnicity of food handlers.

The computed mean values of all items in the measurement scales were high (4.38 and above). Therefore, results should be interpreted with caution and in the context of this study.

Finally, this study utilized a survey and self-reported accounts of behavior. Although steps were taken to mitigate the potential impact of common method bias associated with the cross-sectional self-report method used for identifying food safety behaviors, the behaviors may have not been accurately measured because the participants may have exhibited recall bias.

\section{ACKNOWLEDGMENT}

This study was supported by funds made available from the Foodservice Systems Management Education Council (FSMEC) Grant and the Small Grant Program for Kansas State University Students in Arts, Humanities, and Social Sciences. The funding agencies only provided funds to complete the project as proposed; no input on the research design, methods, data collection and analysis, and/or publication process was received from either funding agency. 


\section{REFERENCES}

1. Abbot, J. M., C. Byrd-Bredbenner, D. Schaffner, C. M. Bruhn, and L. Blalock. 2009. Comparison of food safety cognitions and self-reported food-handling behaviors with observed food safety behaviors of young adults. Eur. J. Clin. Nutr. 63:572-579.

2. Abidin, U. F. U. Z., S. W. Arendt, and C. Strohbehn. 2014. Food safety culture in onsite foodservices: Development and validation of a measurement scale. J. Food Serv. Manag. Educ. 8:1-10.

3. Agarwal, R., and M. J. Dahm. 2015. Success factors in independent ethnic restaurants. J. Foodserv. Bus. Res. 18:20-33.

4. Ahlstrom, D. 2009. Social cognitive predictors of college students' fruit and vegetable intake. Master's thesis. Utah State University. Available at: http:// digitalcommons. usu.edu/cgi/viewcontent. cgi article $=1441 \&$ context $=$ etd. Accessed 7 September 2016.

5. Angelillo, I. F., N. M. Viggiani, L. Rizzo, and A. Bianco. 2000. Food handlers and foodborne diseases: Knowledge, attitudes, and reported behavior in Italy. J. Food Prot. 63:381-385.

6. Armitage, C., and M. Conner. 2000. Social cognition models and health behavior: a structured review. Psychol. Health 15:173-189.

7. Bandura, A. 1986. Social foundations of thought and action. Prentice Hall, Englewood Cliffs, NJ.

8. Bandura, A. 1991. Social cognitive theory of self-regulation. Organ. Behav. Hum. Decis. Process 50:248-287.

9. Bandura, A. 1999. A social cognitive theory of personality, p. 154-196. In L. Pervin and O. John (eds.), Handbook of personality. Guilford Publications, New York, NY.

10. Bandura, A. 2004. Health promotion by social cognitive means. Heal. Educ. Behav. 31:143-164.

11. Bandura, A. 2005. The primacy of selfregulation in health promotion. Appl. Psychol. $54: 245-254$.

12. Bearth, A., M. Cousin, and M. Siegrist. 2014. Investigating novice cooks' behavior change: Avoiding cross-contamination. Food Control 40:26-31.

13. Beavers, A. S., L. Murphy, and J. K. Richards. 2015. Investigating change in adolescent selfefficacy of food safety through educational interventions. J. Food Sci. Edu. 14:54-59.

14. Bektas, M., C. Ozturk, and M. Armstrong. 2010. An approach to children's smoking behaviors using social cognitive learning theory. Asian Pacific J. Canc. Prev. 11:11431149 .

15. Bollen, K. A., \& R. A. Stine. 1992. Bootstrapping goodness-of-fit measures in structural equation models. Sociol. Meth Res. 21:205-229.

16. Brandon, M. 2010. Developing, refining, and validating a survey to measure adolescent food safety self-efficacy, Master's thesis. University of Tennessee, Knoxville. Available at: https://trace.tennessee.edu/cgi/ viewcontent.cgi $?$ article $=1784 \&$ context $=$ utk gradthes. Accessed 15 February 2017.

17. Byrd-Bredbenner, C., V. Wheatley, D. Schaffner, C. Bruhn, L. Blalock, and J. Maurer. 2007. Development of food safety psychosocial questionnaires for young adults. J. Food Sci. Edu. 6:30-37.

18. Church, S., P. Gilbert, and S. Khokhar. 2006. Synthesis report No3: Ethnic groups and foods in Europe. Available at: http://thinkethnic.com/wp-content/ uploads/2012/02/Synthesis\%20 Report\%203_Ethnic\%20groups\%20and\%20 foods\%20in\%20Europe.pdf. Accessed 7 September 2016.

19. Clayton, D. A., C. J. Griffith, P. Price, and A. C. Peters. 2002. Food handlers' beliefs and self-reported practices. Int. J. Environ. Health Res. 12:25-39.

20. Creswell, J. W. 2009. Research design: Qualitative, quantitative, and mixed methods approaches. Third edition. Sage Publications, Inc., Thousand Oaks, CA.

21. De Boeck, E., L. Jacxsens, M. Bollaerts, and P. Vlerick. 2015. Food safety climate in food processing organizations: Development and validation of a self-assessment tool. Trends Food Sci. Technol. 46:242-251.

22. Dharod, J. M., R. Perez-Escamilla, S. Paciello, A. Bermudez-Millan, K. Venkitanarayanan, and G. Damio. 2007. Comparison between self-reported and observed food handling behaviors among Latinas. J. Food Prot. 70:1927-1932.

23. Division of Food safety and Lodging, Kansas Department of Agriculture 2016. A list of licensed restaurants in the state of Kansas.

24. Font, X., L. Garay, and S. Jones. 2016. A social cognitive theory of sustainability empathy. Ann. Tour. Res. 58:65-80.

25. Fulham, E., and B. Mullan. 2011. Hygienic food handling behaviors: Attempting to bridge the intention-behavior gap using aspects from temporal self-regulation theory. J. Food Prot. 74:925-932.

26. Gaines, A., and L. Turner. 2009. Improving fruit and vegetable intake among children: A review of interventions utilizing the social cognitive theory. Californian J. Health Promot. $7: 52-66$

27. Gould, L. H., I. Rosenblum, D. Nicholas, Q. Phan, and T. F. Jones. 2013. Contributing factors in restaurant-associated foodborne disease outbreaks, FoodNet sites, 2006 and 2007. J. Food Prot. 76:1824-1828.

28. Green, L. R. 2008. Behavioral science and food safety. J. Environ. Health 71:47-49.

29. Griffith, C. J., K. M. Livesey, and D. A. Clayton. 2010. Food safety culture: The evolution of an emerging risk factor. $\mathrm{Br}$. Food J. 112: 426-438.

30. Haider, T., M. Sharma, and A. Bernard. 2012 Using social cognitive theory to predict exercise behavior among south Asian college students. J. Community Med. Health Edu. $2: 1-5$.
31. Hall, P. A., and G. T. Fong. 2007. Temporal self-regulation theory: A model for individual health behavior. Health Psychol. Rev. 1:6-52.

32. Hall, P. A., G. T. Fong, L. J. Epp, and L. J. Elias. 2008. Executive function moderates the intention-behavior link for physical activity and dietary behavior. Psychol. Health 23:309-326.

33. Hair, J. F. Jr., W. C. Black, B. J. Babin, R. E. Anderson, and R. L. Tatham. 2006. Multivariate data analysis. Prentice Hall, Upper Saddle River, NJ.

34. Harris, K. J., K. S. Murphy, R. B. DiPietro, and G. L. Rivera. 2015. Food safety inspections results: a comparison of ethnic-operated restaurants to non-ethnic-operated restaurants. Int. J. Hosp. Manag. 46:190-199.

35. Hayes, A. F. 2017. Introduction to mediation, moderation, and conditional process analysis: A regression-based approach. Second edition. Guilford Press, New York, NY.

36. Hinsz, V., and V. Nickell. 2015. The prediction of workers' food safety intentions and behavior with job attitudes and the reasoned action approach. J. Work Org. Psychol. 31:91-100.

37. Howells, A. D., K. R. Roberts, C. W. Shanklin, V. K. Pilling, L. A. Brannon, and B. B. Barrett. 2008. Restaurant employees' perceptions of barriers to three food safety practices. J. Am. Diet. Assoc. 108:1345-1349.

38. Hu, L., and P. M. Bentler. 1999. Cutoff criteria for fit indexes in covariance structure analysis: Conventional criteria versus new alternatives. Struct. Equ. Modeling 6:1-55.

39. Kretzer, E. K., and E. L. Larson. 1998. Behavioral interventions to improve infection control practices. Am. J. Infect. Control 26:245-253.

40. Krueger, R. A., and M. A. Casey. 2000. Focus Group: A practical guide for applied research, 3rd ed. Sage Publications, Inc., Thousand Oaks, CA.

41. Kwasnicka, D., S. U. Dombrowski, M. White, and F. Sniehotta. 2016. Theoretical explanations for maintenance of behaviour change: a systematic review of behaviour theories. Health Psychol. Rev. 10:277-296.

42. Kwon, J., Y. G. Choi, P. Liu, \& Y. M. Lee. 2012. Food safety training needed for Asian restaurants: Review of multiple health inspection data in Kansas. J. Food Serv. Manag. Edu. 6:10-15.

43. Kwon, J., K. R. Roberts, C. W. Shanklin, P. Liu, and W. Yen. 2010. Food safety training needs assessment for independent ethnic restaurants: review of health inspection data in Kansas. Food Prot. Trends 30:412-421.

44. Kwon, D. Y. 2015. What is ethnic food? \{Editorial\}. J. Ethn. Foods. 2:1.

45. Lee, L. E., O. Niode, A. H. Simonne, and C. M. and Bruhn. 2012. Consumer perceptions on food safety in Asian and Mexican restaurants. Food Control 26:531-538. 
46. Lee, J. E., B. A. Almanza, S. Jang, D. C. Nelson, and R. F. Ghiselli. 2013. Does transformational leadership style influence employees' attitudes toward food safety practices? Int. J. Hosp. Manag. 33:282-293.

47. Lee, J., J. Hwang, and A. Mustapha. 2014. Popular ethnic foods in the United States: A historical and safety perspective. Compr. Rev. Food Sci. Food Saf. 13:2-17.

48. Li, D. 2015. Development and assessment of visual-based training on Chinese-speaking foodservice workers in independently-owned Chinese restaurants. Doctoral dissertation. Iowa State University. Available at: https:// lib.dr. iastate.edu/cgi/viewcontent.cgi? article $=5945 \&$ context $=$ etd. Accessed 14 September 2016.

49. Liu, P., J. Kwon, C. W. Shanklin, D. D. Canter and F. J. Webb. 2014. Food safety training attitudes and reported behaviors of Chinese restaurateurs in the United States. Food Prot. Trends 34:300-311.

50. Liu, P., and Y. M. Lee. 2017. An investigation of restaurant food safety performance: a comparison between ethnic and nonethnic and chain and independent restaurants in Louisiana. J. Foodserv. Bus. Res. 20:204-217.

51. Liu, Y., and S. Jang. 2009. Perceptions of Chinese restaurants in the U.S.: What affects customer satisfaction and behavioral intentions? Int. J. Hosp. Manag. 28:338-348.

52. McAlister, A., C. Perry, and G. Parcel. 2008. How individuals, environments, and health behaviors interact: Social cognitive theory, p. 169-188. In K. Glanz, B. Rimer and K. Viswanath (eds.), Health behavior and health education: Theory, research, and practice, Jossey-Bass A Wiley Imprint, San Francisco, CA.

53. Meysenburg, R., J. A. Albrecht, R. Litchfield, P. K. Ritter-Gooder. 2014. Food safety knowledge, practices and beliefs of primary food preparers in families with young children. A mixed methods study. Appetite 73:121-131.

54. Mitchell, R. E., A. M. Fraser, and L. B. Bearon. 2007. Preventing foodborne illness in food service establishments: Broadening the framework for intervention and research on safe food handling behaviors. Int. J. Environ. Health Res. 17:9-24.
55. Morgan, D. L. 1997. Focus groups as qualitative research, 2 nd edition. Sage Publications, Inc., Thousand Oaks, CA.

56. Murphy, K. S., R. B. DiPietro, G. Kock, and J. S. Lee. 2011. Does mandatory food safety training and certification for restaurant employees improve inspection outcomes? Int. J. Hosp. Manage. 30:150-156.

57. Niode, O., C. Bruhn, and A. Simonne. 2011. Insight into Asian and Hispanic restaurant manager needs for safe food handling. Food Control 22:34-42.

58. Nunnally, J. C., and I. H. Bernstein. 1994. Psychometric theory. 3rd edition. McGrawHill, New York, NY.

59. Pilling, V. K., L. A. Brannon, C. W. Shanklin, A. D. Howells, and K. R. Roberts. 2008a. Identifying specific beliefs to target to improve restaurant employees' intentions for performing three important food safety behaviors. J. Am. Diet. Assoc. 108:991-997.

60. Pilling, V. K., L. A. Brannon, C. W. Shanklin, K. R. Roberts, B. B. Barrett, and A. D. Howells. 2008b. Food safety training requirements and food handlers' knowledge and behaviors. Food Prot. Trends 28:192-200.

61. Podsakoff, P. M., S. B. MacKenzie, J.-Y. Lee, and N. P. Podsakoff. 2003. Common method biases in behavioral research: A critical review of the literature and recommended remedies. J. Appl. Psychol. 88:879-903.

62. Powell, D. A., C. J. Jacob, and B. J. Chapman. 2011. Enhancing food safety culture to reduce rates of foodborne illness. Food Control 22:817-822.

63. Rimal, R. 2000. Closing the knowledgebehavior gap in health promotion: The mediating role of self-efficacy. Health Commun. 12:219-237.

64. Roseman, M., Y. Kim, and Y. Zhang. 2013. A study of consumers' intention to purchase ethnic food when eating at restaurants. J. Foodserv. Bus. Res. 16:298-312.

65. Roseman, M., and J. Kurzynske. 2006. Food safety perceptions and behaviors of Kentucky consumers. J. Food Prot. 69:1412-1421.

66. Scholz, U., G. Nagy, W. Göhner, A. Luszczynska, and M. Kliegel. 2009. Changes in self-regulatory cognitions as predictors of changes in smoking and nutrition behaviour. Psychol. Health 24:545-561.

67. Stacey, F. G., E. L. James, K. Chapman, K. S. Courneya, and D. R. Lubans. 2015. A systematic review and meta-analysis of social cognitive theory-based physical activity and/ or nutrition behavior change interventions for cancer survivors. J. Cancer Surviv. 9:305-338

68. Strohbehn, C., M. Shelley, S. Arendt, A. P. Correia, J. Meyer, U. F. U. Z. Abidin, and J. Jun. 2014. Retail foodservice employees' perceptions of barriers and motivational factors that influence performance of safe food behaviors. Food Prot. Trends 34:139-150.

69. Tudoran, A. A., J. Scholderer, K. and Brunsø. 2012. Regulatory focus, self-efficacy and outcome expectations as drivers of motivation to consume healthy food products. Appetite 59:243-251.

70. U.S. Food and Drug Administration. 2009. FDA report on the occurrence of foodborne illness risk factors in selected institutional foodservice, restaurant, and retail food store facility types. Available at: https://wayback. archive-it.org/7993/20170113095300/ http://www.fda.gov/downloads/Food/ GuidanceRegulation/RetailFoodProtection/ FoodborneIllnessRiskFactorReduction/ UCM224682.pdf. Accessed 5 March 2017.

71. Wen, H., and J. Kwon. 2017. Restaurant servers' risk perceptions and risk communication-related behaviors when serving customers with food allergies in the U.S. Int. J. Hosp. Manag. 64:11-20.

72. Yazdanpanah, M, F. R. Feyzabad, M. Forouzani, S. Mohammadzadeh, and R. J. F. Burton. 2015. Predicting farmers' water conservation goals and behavior in Iran: A test of social cognitive theory. Land Use Policy 47:401-407.

73. York, V. K., L. A. Brannon, K. R. Roberts, C. W. Shanklin, and A. D. Howells. 2009. Using the theory of planned behavior to elicit restaurant employee beliefs about food safety: using surveys versus focus groups. J. Foodserv. Bus. Res.12:180-197. 


\section{APPENDIX}

\section{Survey instrument}

Part I: For each statement below, please rate how confident you are that you could perform the following food safety practices.

1. Correctly use a thermometer to determine if food is cooked to a safe temperature

2. Clean and sanitize food contact surfaces before and after preparing food

3. Wash my hands with soap and water for 20 seconds before I begin to prepare food

4. Constantly prepare food in a sanitary manner, even when I am busy with other tasks

5. Perform proper food handling practices to prevent crosscontamination

6. Wash my hands before putting on or changing gloves

7. Wash my hands when food preparation tasks are interrupted or changed

8. Wash my hands after using the restroom, coughing, sneezing, smoking, or touching body parts

9. Use the thermometer to ensure proper food holding temperature

10. Use the thermometer at the completion of reheating food to $165^{\circ} \mathrm{F}$

$\begin{array}{ccccc}\begin{array}{c}\text { Can't do } \\ \text { at all }\end{array} & \begin{array}{c}\text { Can do } \\ \text { a little }\end{array} & \begin{array}{c}\text { Can do } \\ \text { some }\end{array} & \begin{array}{c}\text { Can do } \\ \text { mostly }\end{array} & \begin{array}{c}\text { Can do } \\ \text { for sure }\end{array}\end{array}$

$\begin{array}{lllll}1 & 2 & 3 & 4 & 5 \\ 1 & 2 & 3 & 4 & 5 \\ 1 & 2 & 3 & 4 & 5 \\ 1 & 2 & 3 & 4 & 5 \\ 1 & 2 & 4 & 5 \\ 1 & 2 & 3 & 4 & 5 \\ 1 & 2 & 3 & 4 & 5 \\ 1 & 2 & 3 & 4 & 5 \\ 1 & 2 & 3 & 4 & 5 \\ 1 & 2 & 3 & & 5\end{array}$

Part II: Please indicate your level of agreement with each of the following statements by circling the corresponding number.

11. I closely monitor my handwashing practices during my shift

12. I always evaluate my own handling practices of food and work surfaces

13. I monitor my thermometer use practices to ensure food safety

14. I evaluate my handwashing practices to ensure I follow the proper steps

15. I wash my hands with a goal to ensure food safety

16. I monitor my own handling practices of food and work surfaces

17. I always set a goal to ensure food safety when handling food and work surfaces

18. I evaluate myself when I use a food thermometer

19. I have a goal to ensure food has reached a safe temperature for service and consumption

20. Facilities are adequately equipped to follow safe food handling practices

21. Sufficient financial resources are provided to support hygiene and food safety

22. I get sufficient time to work in a hygienic and safe food way

23. Procedures and instructions concerning food safety are provided to me

\section{Strongly disagree}

\section{Disagree Undecided Agree}

\begin{tabular}{|c|c|c|c|c|}
\hline 1 & 2 & 3 & 4 & 5 \\
\hline 1 & 2 & 3 & 4 & 5 \\
\hline 1 & 2 & 3 & 4 & 5 \\
\hline 1 & 2 & 3 & 4 & 5 \\
\hline 1 & 2 & 3 & 4 & 5 \\
\hline 1 & 2 & 3 & 4 & 5 \\
\hline 1 & 2 & 3 & 4 & 5 \\
\hline 1 & 2 & 3 & 4 & 5 \\
\hline 1 & 2 & 3 & 4 & 5 \\
\hline 1 & 2 & 3 & 4 & 5 \\
\hline 1 & 2 & 3 & 4 & 5 \\
\hline 1 & 2 & 3 & 4 & 5 \\
\hline 1 & 2 & 3 & 4 & 5 \\
\hline
\end{tabular}


APPENDIX (continued)

Survey instrument

\begin{tabular}{|c|c|c|c|c|c|}
\hline & $\begin{array}{l}\text { Strongly } \\
\text { disagree }\end{array}$ & Disagree & Undecided & Agree & $\begin{array}{l}\text { Strongly } \\
\text { agree }\end{array}$ \\
\hline $\begin{array}{l}\text { 24. The necessary infrastructure and equipment (e.g., handwashing } \\
\text { sinks) are available and accessible to support food safety }\end{array}$ & 1 & 2 & 3 & 4 & 5 \\
\hline $\begin{array}{l}\text { 25. My manager/supervisor enforces food safety rules consistently } \\
\text { with employees }\end{array}$ & 1 & 2 & 3 & 4 & 5 \\
\hline $\begin{array}{l}\text { 26. My manager/supervisor inspires me to follow proper food safety } \\
\text { practices }\end{array}$ & 1 & 2 & 3 & 4 & 5 \\
\hline $\begin{array}{l}\text { 27. My coworkers are always supportive of each other regarding food } \\
\text { safety }\end{array}$ & 1 & 2 & 3 & 4 & 5 \\
\hline $\begin{array}{l}\text { 28. My manager/supervisor is actively involved to ensure safe food } \\
\text { handling is practiced }\end{array}$ & 1 & 2 & 3 & 4 & 5 \\
\hline 29. Sufficient education and food safety training are provided & 1 & 2 & 3 & 4 & 5 \\
\hline 30. I intend to use a food thermometer at the completion of cooking & 1 & 2 & 3 & 4 & 5 \\
\hline 31. I plan to wash my hands whenever it is required & 1 & 2 & 3 & 4 & 5 \\
\hline 32. I am willing to clean and sanitize food contact surfaces between each use & 1 & 2 & 3 & 4 & 5 \\
\hline 33. I plan to use a food thermometer at the completion of reheating food & 1 & 2 & 3 & 4 & 5 \\
\hline $\begin{array}{l}\text { 34. I intend to use a food thermometer to check the temperature on } \\
\text { the hot line/cold line }\end{array}$ & 1 & 2 & 3 & 4 & 5 \\
\hline $\begin{array}{l}\text { 35. I am willing to separate raw food from ready-to-eat food during } \\
\text { preparation }\end{array}$ & 1 & 2 & 3 & 4 & 5 \\
\hline
\end{tabular}

Part III: Using the stem "If I follow proper food safety practices regarding handwashing, use of thermometer, and handling of food and work surfaces ", please circle your response to each of the following statements.

If I follow proper food safety practices regarding handwashing, use of thermometer, and handling of food and work surfaces:

\begin{tabular}{|c|c|c|c|}
\hline $\begin{array}{c}\text { Very } \\
\text { unlikely }\end{array}$ & Unlikely & $\begin{array}{l}\text { Somewhat } \\
\text { likely }\end{array}$ & Likely \\
\hline
\end{tabular}

36. I will help protect my restaurant from liability for foodborne illnesses

37. my manager/supervisor will praise my performance

38. I will not be able to focus on primary tasks of preparation and cooking

39. customers will be satisfied

40. I will reduce the risk of foodborne illnesses

41. I will feel a sense of accomplishment

42. I will help protect the reputation of my restaurant

43. I will avoid losing my job unlikely

Unlikely 
APPENDIX (continued)

\section{Survey instrument}

Part IV: Please indicate how often you perform the following food safety behaviors by circling the corresponding number.

44. I wash my hands when starting shift

45. I wash my hands before putting on or changing gloves

46. I wash my hands after sneezing, coughing, or using a tissue

47. I wash my hands before and after handling raw food

48. I wash my hands after touching anything that may contaminate hands (chemicals, non-sanitized work surfaces, body parts)

\begin{tabular}{|c|c|c|c|c|}
\hline Never & Rarely & Sometimes & Often & Always \\
\hline 1 & 2 & 3 & 4 & 5 \\
\hline 1 & 2 & 3 & 4 & 5 \\
\hline 1 & 2 & 3 & 4 & 5 \\
\hline 1 & 2 & 3 & 4 & 5 \\
\hline 1 & 2 & 3 & 4 & 5 \\
\hline 1 & 2 & 3 & 4 & 5 \\
\hline 1 & 2 & 3 & 4 & 5 \\
\hline 1 & 2 & 3 & 4 & 5 \\
\hline 1 & 2 & 3 & 4 & 5 \\
\hline 1 & 2 & 3 & 4 & 5 \\
\hline 1 & 2 & 3 & 4 & 5 \\
\hline 1 & 2 & 3 & 4 & 5 \\
\hline
\end{tabular}

Part V: Demographic and Operational Information

Please answer the following questions about you and the operation in which you work.

\section{What is your age?}

years

\section{7 . What is your gender?}
A. Male
B. Female

58. What is your ethnicity?
A. Caucasian
B. Hispanic or Latino
C. African American
D. Native American
E. Asian
F. Pacific Islander
G. Other, please specify: 


\section{APPENDIX (continued)}

\section{Survey instrument}

\section{What is your highest level of education?}
A. Less than high schoo
B. High school/GED
C. Associate degree
D. Some college
E. Bachelor's degree
F. Graduate degree

60. Which of the following most accurately describes your role?
A. Line cook
B. Prep cook
C. Executive chef
D. Other, please specify:

61. How long have you been employed in foodservice?
A. 5 years or less
B. $6-15$ years
C. $16-25$ years
D. 26 years or more

62. How would you describe your operation?
A. Independent
B. Part of a chain
C. Other, please specify:

63. The theme of your restaurant is:
A. Chinese
B. Mexican
C. Other, please specify:

64. How would you classify your service?
A. Quick service (Fast food)
B. Quick casual
C. Casual dining
D. Fine dining
E. Buffet

65. Have you received food safety training in the past year?
A. Yes
B. No

66. Do you have a current food safety certification?

A. Yes, please specify:

B. No 